Etnográfica

Revista do Centro em Rede de Investigação em

Antropologia

vol. $14(3) \mid 2010$

Vol. 14 (3)

\title{
António Medeiros, Benjamim Pereira e João Alpuim Botelho, Uma Imagem da Nação: Traje à Vianesa
}

\section{Luís Cunha}

\section{OpenEdition \\ Journals}

Edição electrónica

URL: https://journals.openedition.org/etnografica/226

DOI: 10.4000/etnografica.226

ISSN: 2182-2891

\section{Editora}

Centro em Rede de Investigação em Antropologia

\section{Edição impressa}

Data de publição: 1 outubro 2010

Paginação: 617-630

ISSN: 0873-6561

\section{Refêrencia eletrónica}

Luís Cunha, «António Medeiros, Benjamim Pereira e João Alpuim Botelho, Uma Imagem da Nação: Traje à Vianesa», Etnográfica [Online], vol. 14 (3) | 2010, posto online no dia 04 outubro 2011, consultado o 12 fevereiro 2022. URL: http://journals.openedition.org/etnografica/226 ; DOI: https://doi.org/10.4000/ etnografica.226

Este documento foi criado de forma automática no dia 12 fevereiro 2022

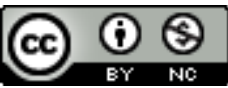

Etnográfica is licensed under a Creative Commons Attribution-NonCommercial 4.0 International License. 


\title{
António Medeiros, Benjamim Pereira e João Alpuim Botelho, Uma Imagem da Nação: Traje à Vianesa
}

\author{
Luís Cunha
}

\section{REFERÊNCIA}

António Medeiros, Benjamim Pereira e João Alpuim Botelho, Uma Imagem da Nação: Traje à Vianesa. Viana do Castelo, Câmara Municipal de Viana do Castelo, 392 páginas. 2009

1 O que esteve na origem da elaboração de Uma Imagem da Nação: Traje à Vianesa serve como prova adequada, não apenas da relevância do que a obra nos mostra, mas também da abrangência e transversalidade simbólica daquilo que a motivou: o traje à vianesa. $\mathrm{A}$ pretexto da comemoração dos 750 anos da outorga do foral a Viana do Castelo, a edilidade municipal decidiu desafiar Benjamim Enes Pereira para a realização de um estudo dedicado àquela que ao longo de muitas décadas, e ainda hoje, constitui uma forte marca identitária da região. A justificação desse convite tem tanto de simples como de revelador em relação ao que se jogava no projecto. Como nota o presidente do município na "Apresentação" da obra, trata-se de dar relevo a um símbolo reconhecido, desde há muito associado a Viana do Castelo, mas que, apesar dessa antiguidade, permanece vivo e dinâmico. A escolha do traje a pretexto de um acontecimento histórico tão remoto como a atribuição de um foral no século XIII é reveladora da importância que o município lhe atribui na configuração de uma identidade regional e seu reconhecimento nacional. Mas essa escolha mostrou também que, apesar de tudo quanto se escreveu sobre o tema, havia ainda uma história para contar - ou recontar, pouco importa para o caso. Uma história feita de datas e acontecimentos, mas também de discursos que configuram desejos e conflitos, visões e objectivos, ora contrastantes, ora confluentes. Foi com estes materiais, abundantes mas difusos, que os autores se abalançaram à escrita de Uma Imagem da Nação: Traje à Vianesa. Concretizaram-no como 
um trabalho de equipa, partindo de diferentes focalizações, mas certos de encontrar uma complementaridade que assegurasse um resultado final adequado às elevadas expectativas de que a proposta partiu.

Lendo Uma Imagem da Nação: Traje à Vianesa, percebe-se com clareza a divisão de tarefas e através dela a lógica formal que enformou o trabalho. António Medeiros, no capítulo a que chamou "Um traje da nação", retoma algumas questões que trabalhou em outros lugares e ocasiões, procurando dar conta do modo como se foram construindo as representações em torno do traje e, mais amplamente, do modo de imaginar o Minho. $\mathrm{O}$ contributo de Benjamim Pereira, em "O traje dito à vianesa" tem um sentido diferente, alicerçando-se, fundamentalmente, num enorme conhecimento técnico e atenção ao detalhe para elaborar uma verdadeira etnografia do traje, que vai desde o cultivo das matérias-primas às diferentes formas de uso do produto acabado. Finalmente, da parte de João Alpuim Botelho, é-nos oferecido um outro olhar sobre o mesmo objecto, no caso através da construção de uma cronologia extensa, que nos oferece uma panorâmica sobre o modo como o traje foi sendo usado e pensado ao longo do tempo, tendo como pano de fundo a história regional, nacional e mesmo internacional.

Destes três contributos, julgamos poder dizer que os dois primeiros dialogam efectivamente entre si, enquanto o terceiro, muito embora revele um significativo trabalho de recolha de dados, acaba por surgir de uma forma algo desgarrada, quase como um apêndice ao trabalho. Voltaremos a esta questão. António Medeiros vale-se do seu vasto e consistente conhecimento da realidade minhota para construir uma visão diacrónica, não só do traje vianense ou à lavradeira, mas também das envolventes sociais e políticas que lhe dizem respeito. Trata-se de uma abordagem útil e esclarecedora, pois permite perceber o processo de fixação de um determinado padrão de traje e as diferentes forças e interesses que nele se envolvem. Percebemos, assim, as dinâmicas e as estratégias privilegiadas nesse longo processo, sejam elas os desfiles de trajes e cortejos etnográficos que gradualmente, e a partir do modelo desenvolvido em contexto urbano, "contaminam" as freguesias rurais (p. 39), ou o crescimento dos ranchos folclóricos em todo o concelho. Muito embora esta seja uma obra pensada para o "grande público" e com intuitos essencialmente de divulgação, a verdade é que isso não obsta à convocação de questões de maior profundidade, como podem ser as do diálogo entre tradição e modernidade ou as decorrentes de um olhar para outras realidades nacionais, igualmente marcadas pela promoção do traje no processo mais amplo de afirmação das identidades nacionais.

O capítulo escrito por Benjamim Pereira constituirá, certamente, um marco importante para uma etnografia do traje à vianesa. Dividido em três partes, o seu contributo oferece-nos, em primeiro lugar, uma panorâmica geral sobre o tema, recorrendo a escritos fundacionais, como os que nos legaram Ramalho Ortigão ou Cláudio Basto. Por outro lado, e ainda nesta parte introdutória, o autor traça algumas distinções no traje usado em diferentes regiões de Viana. Na segunda parte, Benjamim Pereira ocupa-se das matérias-primas usadas na confecção do traje, dando-nos a conhecer os ciclos da lã e do linho e o modo como se foram modificando ao longo do tempo - e não apenas isso, note-se, mas, por exemplo, também o modo como se tem procurado recuperar, através de práticas performativas, a tradição do linho (p. 148). A parte final deste capítulo é dedicada a mostrar o modo de produção dos tecidos e de confecção dos trajes, de uma forma que apenas um conhecimento profundo do terreno, como é o de Benjamim Enes Pereira, possibilita. 
Como dissemos, estas duas partes complementam-se e articulam-se de uma forma que nos parece bastante pertinente. Em ambos os casos, o olhar constrói-se numa lógica diacrónica, sempre atenta, por isso, às dinâmicas sociais e políticas que levaram à fixação do traje à vianesa e à sua promoção a emblema regional e mesmo nacional. Neste sentido, o terceiro capítulo de Uma Imagem da Nação: Traje à Vianesa acaba por se mostrar nalguns casos redundante e, noutros, algo irrelevante. Percebe-se a dificuldade da proposta. Conseguir criar uma cronologia pertinente, que desse conta, simultaneamente, do percurso do traje à vianense e dos acontecimentos da história nacional e mundial (p. 238), seria sempre tarefa complexa. Para lá dos critérios usados, inevitavelmente discutíveis, colocar-se-ia também a questão do equilíbrio entre os diferentes registos convocados. Nada disto põe em causa, evidentemente, o enorme esforço de recolha e sistematização de material, nem mesmo o que essa recolha significa no enriquecimento da obra e se oferece como um corpus incontornável para futuras abordagens deste tema. É na economia da obra, na sua arquitectura interna, que este contributo revela as fragilidades a que aludimos.

Estamos perante um trabalho profundo, que consegue, todavia, conciliar o rigor com uma linguagem apelativa, capaz de suscitar interesse num público vasto, habitualmente distanciado da linguagem e das problematizações marcadamente académicas. Este não é, certamente, o menor dos méritos desta obra, pois é esse compromisso, entre a divulgação e o rigor, que permite a afirmação de qualquer disciplina para lá dos muros, demasiadamente fechados, da universidade. Trata-se, como vimos, de uma obra compósita, que junta contributos de diferentes autores, que não só se distinguem pela forma como abordam o tema, mas também pelos diferentes percursos pessoais e profissionais de cada um deles. Poderia resultar daqui uma manta de retalhos, mas não é isso que sucede. Para lá do que já foi dito, e que decorre da conceptualização da obra, há ainda um outro factor a considerar na eficácia do resultado final. Trata-se das ilustrações que enriquecem Uma Imagem da Nação: Traje à Vianesa e são, pode dizer-se, a sua alma. Reveladoras de um exaustivo trabalho de recolha, elas conseguem, quase sempre, um efectivo diálogo com o texto, funcionando, por essa razão, como o cimento que sustenta o edifício e lhe dá consistência. Com as inúmeras fotografias, cartazes e reproduções pictóricas, consegue-se ainda um outro efeito importante, uma espécie de elisão do tempo - o que não deixa de ser um efeito algo paradoxal, atendendo a que toda a obra se constrói numa lógica diacrónica. As fotos actuais, mais ou menos encenadas, dialogam com as antigas, nas quais a encenação, quando existe, tem um outro sentido. As diferenças, que evidentemente existem, são subsumidas nas semelhanças, que criam a ilusão de estarmos perante uma realidade quase imutável, uma insuspeita atemporalidade marcando o uso deste traje. É neste sentido que falamos de elisão do tempo, fenómeno que nos parece bastante sugestivo para discutir os processos de patrimonialização e a actualização das narrativas que dão sentido a tais processos. 